\title{
El Máster en Formación del Profesorado de Música en Educación Secundaria y Bachillerato: análisis de los planes de estudio desde la perspectiva de la sociedad y economía del conocimiento
}

\author{
Master in Music Teacher Education: Analysis of programs from the perspective of the \\ knowledge-based society and economy
}

\author{
Rosa M. Serrano \\ rmserran@unizar.es \\ Departamento de Expresión Musical, Plástica y Corporal \\ Universidad de Zaragoza \\ Zaragoza, España \\ ORCID: http://orcid.org/0000-0003-3704-3533 \\ Felipe Javier Zamorano Valenzuela \\ felipe.zamorano.v@gmail.com \\ Universidad de Granada \\ Granada, España \\ ORCID: http://orcid.org/0000-0002-1309-4726
}

Cristina González-Martín Cristina.Gonzalez.Martin@uab.cat

Departamento de Didáctica de la Expresión Musical, Plástica y Corporal Universidad Autónoma de Barcelona

Barcelona, España

ORCID: http://orcid.org/0000-0002-1762-9425

doi: 10.7203/LEEME.46.17600

Recibido: 14-06-2020 Aceptado: 29-07-2020. Contacto y correspondencia: Rosa M. Serrano. Departamento de Expresión Musical, Plástica y Corporal, Universidad de Zaragoza, C/Pedro Cerbuna, 12, C.P. 50009 Zaragoza. España.

\section{Resumen}

El presente artículo tiene como objetivo conocer la adecuación de la planificación que por escrito ofrecen los programas españoles de formación del profesorado de Música de Educación Secundaria y Bachillerato en relación a las demandas de la escuela y el aula de Música en la actual sociedad y economía del conocimiento. Para ello, se realiza un análisis documental comparado de los planes de estudio de 26 Másteres en Profesorado que ofrecen la especialidad de música en el territorio español. Los resultados se platean tanto de manera general, describiendo denominaciones, competencias, estructuras y créditos de los planes de estudio; como de manera específica, definiendo tipologías en las materias de los módulos específico musical y Prácticum. Se concluye que ciertos planes de estudio promueven la construcción de capacidades fundamentales para dar respuesta a la sociedad y economía del conocimiento, como la reflexividad colegiada y la interdisciplinariedad, el pensamiento creativo y el emprendimiento, la integración tecnológica y la innovación, así como la sensibilidad sobre temas sociales. Si bien no es actualmente la orientación universitaria más habitual, pues todavía los planes de estudios están centrados en la adaptación y la perpetuación de modelos eminentemente academicistas, permite ofrecer una visión positiva de apuesta hacia una formación del profesorado deseable para todos los planes docentes.

Palabras clave: Economía del conocimiento; sociedad del conocimiento; formación del profesorado de música; planes de estudio.

\begin{abstract}
The goal of this article is to analyse the adequacy of the written programs offered by Spanish universities in relation to the training of High School music teachers to the demands of schools and music classrooms in the knowledge-based society and economy. To reach this goal, a comparative documentary analysis of the programs of 26 Masters that offer music teacher education in Spain is executed. The results both in a general way, describing denominations, competences, structures, and credits of the programs; as well as in a specific way, defining typologies in the musical modules and practical training are presented. The conclusion is drawn that certain programs promote the construction of fundamental capacities to respond to the knowledge-based society and economy, such as reflective collective thinking and interdisciplinarity, creative thinking and entrepreneurship, technological integration, and innovation, as well as sensitivity to social issues. Although currently this is not the most common university orientation, since music teacher programs are still focused on the adaptation and perpetuation of eminently academic models, it does offer a positive vision of a commitment to teacher training that is desirable for all university programs.

Key words: Knowledge economy; knowledge society; music teacher training; curricula.
\end{abstract}

@Rosa María Serrano Pastor, Felipe Javier Zamorano Valenzuela y Cristina González Martín. The content of this article is the sole responsibility of the authors. The Revista Electrónica de LEEME and Universitat de València are not liable for any legal actions that may arise involving the article's content. Revista Electrónica de LEEME - Lista Electrónica Europea de Música en la Educación-. http://ojs.uv.es/index/php/LEEME/index ISSN: 1575-9563. Editores: Universidad de Valencia y Jesús Tejada. Visibilidad de esta revista: SCOPUS, Emerging Sources Citation Index (Clarivate), EBSCO, CINDOC (CSIC), Citefactor, COPAC, Dialnet, DICE (CSIC), DOAJ, e-revistas (CSIC), EBSCO Premier, ERIH+, Gale Cengage Learning, IN-RECS, IRESIE, LATINDEX, MIAR, OCLC Worldcat, RESH, REDIB, RILM Core Journals, SUDOC, ULRICHS. Esta revista es de acceso libre mediante licencia Creative Commons $4.0 \mathrm{CC}$ by. Política de archivado: etiqueta verde SHERPA-ROMEO. 


\section{Introducción}

La nueva modernidad y sus avances tecnológicos han llevado a que los espacios de producción económica se diversifiquen y sitúen al campo de la información y las ideas en el centro del aparato productivo de las economías modernas (Stehr, 2007). La sociedad del conocimiento (Drucker, 1993), como producto de la globalización y el desarrollo tecnológico, gira en torno al crecimiento acelerado del conocimiento, la disposición hacia la innovación y el sustento medial a través de interfaces tecnológicas (Aróstegui, 2017). Por ello, puede afirmarse que "el valor de las sociedades actuales está directamente relacionado con el nivel de formación de sus ciudadanos y de la capacidad de innovación y emprendimiento que éstos posean" (Marcelo, 2001, p.532). Formación del capital humano que depende en gran medida de la educación formal recibida y ofrecida en los diferentes niveles educativos, y desde las diferentes áreas del currículum. Entre dichas áreas, las artes en general y la música en particular encuentran su espacio al favorecer la creatividad (Ceschini, 2014) y la innovación (Robelen, 2011) en tanto factores determinantes para la productividad y la prosperidad del mundo laboral (Jamil y otros, 2018). Esto conlleva que la formación del profesorado a cargo de estas resulte esencial, pues es el último intermediario entre los propósitos del sistema educativo y el alumnado (Lucato, 2001). Actualmente, en el contexto español, la formación inicial del profesorado de música consiste en un grado de educación acompañado de una mención en educación musical si quiere desarrollar su función en la etapa de Educación Infantil y Primaria; y un Máster en Formación del Profesorado si quiere desarrollarla en la etapa de Educación Secundaria Obligatoria y Bachillerato.

En general, la preocupación por la formación inicial docente resulta de interés ya que su estudio permite mejorar y optimizar el proceso educativo (Domínguez y Prieto, 2019). Así lo muestran diferentes estudios tanto de ámbito internacional (Manso y otros, 2019; Vaillant, 2019) como nacional (Cid y otros, 2012; Escudero y otros, 2019; Hernández y Carrasco, 2012; Pontes y otros, 2010). En el ámbito específico musical, también existe cierta inquietud, aunque son escasos los estudios. Encontramos algunas evidencias en las enseñanzas de régimen especial (Riveiro, 2014), en la educación musical infantil (García-Gil y Bernabé, 2019), y la mayoría de ellos en la educación primaria (Aróstegui y Cisneros-Cohernour, 2010).

En lo que respecta al análisis de los actuales planes de estudio del Máster en Educación Secundaria y Bachillerato en la especialidad de Música (en adelante, MESM) apenas se cuenta con el estudio de López y Bermell (2016), que presentó las universidades españolas que ofertan la especialidad musical y la distribución de asignaturas y créditos que poseen. Es por ello que, tras una década de implantación de los nuevos planes de estudio, resulta más que urgente realizar un análisis en profundidad de cómo han cristalizado en cada una de las universidades españolas. El objetivo de esta investigación es conocer la adecuación de la planificación que por escrito ofrecen los programas españoles de formación del profesorado de Música de Educación

@Rosa María Serrano Pastor, Felipe Javier Zamorano Valenzuela y Cristina González Martín. The content of this article is the sole responsibility of the authors. The Revista Electrónica de LEEME and Universitat de València are not liable for any legal actions that may arise involving the article's content. Revista Electrónica de LEEME - Lista Electrónica Europea de Música en la Educación-. http://ojs.uv.es/index/php/LEEME/index ISSN: 1575-9563. Editores: Universidad de Valencia y Jesús Tejada. Visibilidad de esta revista: SCOPUS, Emerging Sources Citation Index (Clarivate), EBSCO, CINDOC (CSIC), Citefactor, COPAC, Dialnet, DICE (CSIC), DOAJ, e-revistas (CSIC), EBSCO Premier, ERIH+, Gale Cengage Learning, IN-RECS, IRESIE, LATINDEX, MIAR, OCLC Worldcat, RESH, REDIB, RILM Core Journals, SUDOC, ULRICHS. Esta revista es de acceso libre mediante licencia Creative Commons $4.0 \mathrm{CC}$ by. Política de archivado: etiqueta verde SHERPA-ROMEO. 


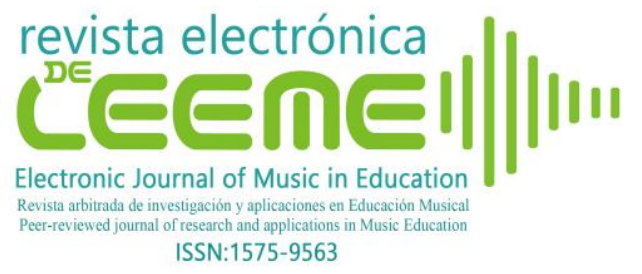

Rosa M. Serrano, Felipe Javier Zamorano y Cristina González Martín

El Máster en Profesorado de Música: análisis de los planes de estudio desde la perspectiva de la sociedad y economía del conocimiento (Revista Electrónica de LEEME) Número 48, pp. 187-207 https://ojs.uv.es/index.php/LEEME/index

Secundaria y Bachillerato en relación a las demandas de la escuela y el aula de Música en la actual sociedad y economía del conocimiento (en adelante, SyEC).

\subsection{Tradiciones y modelos didácticos en la formación del profesorado de Música}

Los planes de estudio se establecen como espacio en donde se detalla el conjunto de enseñanzas que debe cursar el alumnado para obtener determinado conocimiento. La articulación de estos planes de estudio es diversa y compleja, e intereses educativos, políticos e institucionales dan el sello a cada uno de ellos, plasmándose sus concepciones y focos específicos de la práctica reflexiva del profesorado (Liston y Zeichner, 1997).

En el caso de la formación del profesorado de Música, estos intereses educativos despliegan fronteras articuladas por creencias y prácticas que, según Ballantyne (2007), presentan especialmente características de las tradiciones academicista y de eficiencia social. Como complemento, Nierman y otros (2002) matizan estas interpretaciones, apuntando que el profesorado de Música recorrería, aunque en menor medida, la tradición desarrollista al promover la reflexión docente en base a motivaciones y pautas de los estadios psicológicos de los estudiantes, y la tradición de reconstrucción social donde la reflexión está dirigida hacia su propia práctica y las problemáticas socioculturales que rodean la escuela (Zeichner, 2005).

Con un foco más específico, Jorquera (2010) propone cuatro modelos didácticos para caracterizar las creencias y prácticas del profesorado de música, dividiendo entre los modelos academicista, práctico, comunicativo lúdico y complejo. Es este último donde el profesorado se posiciona críticamente ante el currículum con una visión que aúna la música, los intereses del alumnado y la sociedad (Aróstegui, 2011).

\subsection{El aula de Música y el profesionalismo creativo}

Las nuevas dinámicas sociales, culturales y económicas exigen una reconfiguración de la formación del profesorado de Música. La escuela y el aula musical se han visto envueltas en dichas dinámicas, convirtiéndose en un espacio físico y virtual con diversas culturas musicales (Kertz-Welzel, 2018). Por tanto, los escenarios educativos a los que se exponen los profesionales de la educación necesitan que estos activen nuevas disposiciones y formas de trabajo, generando conocimiento alternativo (política generativa) y estableciendo redes de trabajo y relaciones horizontales a partir de la confianza en los otros (confianza activa) (Giddens, 1998).

La SyEC demanda un profesorado capaz de promover y gestionar el conocimiento "infinito" al que tienen acceso los estudiantes. Ya no se trata de memorizar los contenidos y las formas de hacer (Aróstegui, 2017), sino de generar nuevas lógicas de construcción del conocimiento, individualmente y en red, para que los estudiantes desarrollen "habilidades de

@Rosa María Serrano Pastor, Felipe Javier Zamorano Valenzuela y Cristina González Martín. The content of this article is the sole responsibility of the authors. The Revista Electrónica de LEEME and Universitat de València are not liable for any legal actions that may arise involving the article's content. Revista Electrónica de LEEME - Lista Electrónica Europea de Música en la Educación-. http://ojs.uv.es/index/php/LEEME/index ISSN: 1575-9563. Editores: Universidad de Valencia y Jesús Tejada. Visibilidad de esta revista: SCOPUS, Emerging Sources Citation Index (Clarivate), EBSCO, CINDOC (CSIC), Citefactor, COPAC, Dialnet, DICE (CSIC), DOAJ, e-revistas (CSIC), EBSCO Premier, ERIH+, Gale Cengage Learning, IN-RECS, IRESIE, LATINDEX, MIAR, OCLC Worldcat, RESH, REDIB, RILM Core Journals, SUDOC, ULRICHS. Esta revista es de acceso libre mediante licencia Creative Commons 4.0 CC by. Política de archivado: etiqueta verde SHERPA-ROMEO. 


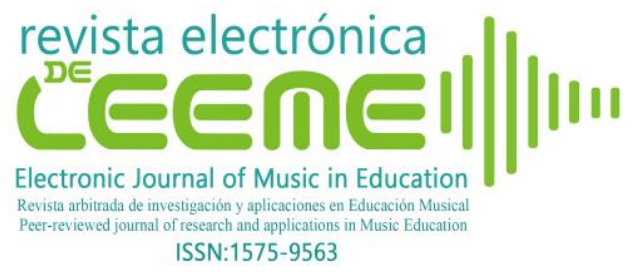

Rosa M. Serrano, Felipe Javier Zamorano y Cristina González Martín El Máster en Profesorado de Música: análisis de los planes de estudio desde la perspectiva de la sociedad y economía del conocimiento (Revista Electrónica de LEEME) Número 48, pp. 187-207 https://ojs.uv.es/index.php/LEEME/index

razonamiento de alto nivel y de pensamiento creativo que necesitan para poder remodelar la sociedad" (Scheib, 2006, p.11).

La creación de estas nuevas formas de aprender implica el desarrollo de profesionales dispuestos a entender su trabajo vinculado a la innovación y actualización (Marcelo, 2001). Estos docentes deben estar abiertos a la experimentación de nuevas formas de enseñanza y aprendizaje, con una alta sensibilidad cultural que permita ofrecer nuevas oportunidades musicales a sus estudiantes (Kertz-Welzel, 2018). Además, este profesorado debe apoyarse en redes de colaboración, pues la complejidad de las nuevas condiciones de la SyEC necesita confianza y apoyo de un tejido profesional para el desarrollo de nuevos proyectos educativos (Marcelo, 2001). Dichas redes profesionales favorecen el diálogo interdisciplinar y la exploración de nuevas formas de pensar el mundo educativo desde una reflexividad colegiada (Torres, 2006). Por ello se consideran esenciales para desarrollar la capacidad de negociación del profesorado, el currículum integrado y la flexibilidad que demanda la SyEC.

\section{Método}

Se ha llevado a cabo una investigación cualitativa basada en el análisis documental. Este método se puede definir como un proceso de análisis y síntesis de los datos recogidos en documentos y "como medio para organizar y representar el conocimiento registrado en los mismos" (Peña y Pirela, 2007, p.59) elaborando una nueva representación de su contenido que permite el crecimiento intelectual (Fox, 2005).

El análisis documental se ha efectuado con los datos extraídos de las páginas web de las universidades y de las guías docentes de cada una de las asignaturas musicales. Dichas guías son un marco de planificación común para todas las universidades que intenta dar transparencia a los procesos de formación (Gil-Asensio, 2008), por lo que se hace necesario su estudio pormenorizado. Si bien todas las universidades analizadas poseen página web donde ofrecen información al respecto, no en todas están presentados los datos con el mismo detalle ni están elaboradas las guías con la misma coherencia y minuciosidad. A dicho análisis documental se le ha aplicado un método comparativo en base a unas categorías, que se concretan posteriormente, con el objetivo de buscar similitudes y disimilitudes (Fideli, 1998). La utilidad de este enfoque comparado es reconocida en el ámbito de la educación en la formación del profesorado (Popkewitz y Pereyra, 1994) como medio para favorecer la comprensión de las dinámicas que subyacen en sus planes de estudio.

Finalmente, este análisis documental centrado en exponer la planificación que las universidades ofrecen en los estudios de profesorado del Máster de Música son el reflejo de un constructo legislativo que muestra lo que cada universidad se propone en dicha titulación y permite obtener información sobre la diversidad de los planes de estudio existente. Esta

@Rosa María Serrano Pastor, Felipe Javier Zamorano Valenzuela y Cristina González Martín. The content of this article is the sole responsibility of the authors. The Revista Electrónica de LEEME and Universitat de València are not liable for any legal actions that may arise involving the article's content. Revista Electrónica de LEEME - Lista Electrónica Europea de Música en la Educación-. http://ojs.uv.es/index/php/LEEME/index ISSN: 1575-9563. Editores: Universidad de Valencia y Jesús Tejada. Visibilidad de esta revista: SCOPUS, Emerging Sources Citation Index (Clarivate), EBSCO, CINDOC (CSIC), Citefactor, COPAC, Dialnet, DICE (CSIC), DOAJ, e-revistas (CSIC), EBSCO Premier, ERIH+, Gale Cengage Learning, IN-RECS, IRESIE, LATINDEX, MIAR, OCLC Worldcat, RESH, REDIB, RILM Core Journals, SUDOC, ULRICHS. Esta revista es de acceso libre mediante licencia Creative Commons $4.0 \mathrm{CC}$ by. Política de archivado: etiqueta verde SHERPA-ROMEO. 


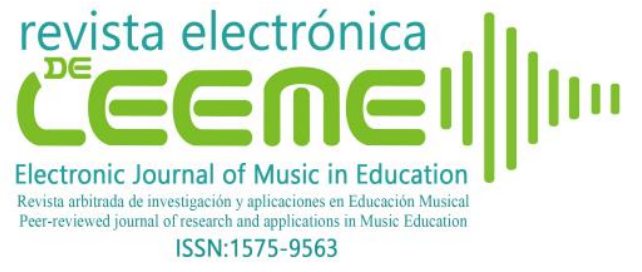

Rosa M. Serrano, Felipe Javier Zamorano y Cristina González Martín El Máster en Profesorado de Música: análisis de los planes de estudio desde la perspectiva de la sociedad y economía del conocimiento (Revista Electrónica de LEEME) Número 48, pp. 187-207 $\frac{\text { https://ojs.uv.es/index.php/LEEME/index }}{\text { DOI. } 10.7203 / \text { LEEME } 46.17600}$

información resulta valiosa, a modo teórico y formal, para poder ser contrastada en una segunda fase de la investigación con la realidad de la práctica del aula.

\subsection{Muestra}

Se han analizado todos los planes de estudio de MESM en España, con especial énfasis en las asignaturas musicales. En concreto, se han examinado un total de 26 planes de estudio ofrecidos por diferentes universidades españolas durante los cursos 2018/2019 y/o 2019/2020, tal y como muestra la siguiente tabla:

Tabla 1. Lista de universidades que ofrecen Máster de Secundaria y Bachillerato especialidad de Música

\begin{tabular}{ccc}
\hline COMUNIDAD & UNIVERSIDAD & CARÁCTER \\
\hline ANDALUCÍA & U. DE GRANADA & Pública \\
& U. DE SEVILLA & Pública \\
& U. DE MÁLAGA & Pública \\
ARAGÓN & U. DE CÓRDOBA & Pública \\
ASTURIAS & U. DE ZARAGOZA & Pública \\
CASTILLA Y LEÓN & U. DE OVIEDO & Pública \\
& U. DE VALLADOLID & Pública \\
CATALUÑA & U. DE SALAMANCA & Pública \\
& U. PONTIFICIA DE SALAMANCA & Privada \\
COMUNIDAD VALENCIANA & U. DE BARCELONA & Pública \\
& U. DE ALICANTE & Pública \\
EXTREMADURA & U. JAUME I & Pública \\
GALICIA & U. DE VALENCIA & Pública \\
& U. CATÓLICA DE VALENCIA SAN VICENTE MÁRTIR & Privada \\
ISLAS BALEARES & U. INTERNACIONAL DE VALENCIA & Privada \\
ISLAS CANARIAS & U. DE EXTREMADURA & Pública \\
MADRID & U. DE LA CORUÑA & Pública \\
& U. DE SANTIAGO DE COMPOSTELA & Pública \\
& U. DE LAS ISLAS BALEARES & Pública \\
& U. DE LA LAGUNA & Pública \\
& U. DE LAS PALMAS DE GRAN CANARIA & Pública \\
& U. AUTÓNOMA DE MADRID & Pública \\
& U. COMPLUTENSE DE MADRID & Pública \\
& U. DE MUROPEA SAN ANTONIO DE MURCIA & Pública \\
& Privada \\
\hline
\end{tabular}

Fuente: Elaboración propia

@Rosa María Serrano Pastor, Felipe Javier Zamorano Valenzuela y Cristina González Martín. The content of this article is the sole responsibility of the authors. The Revista Electrónica de LEEME and Universitat de València are not liable for any legal actions that may arise involving the article's content. Revista Electrónica de LEEME - Lista Electrónica Europea de Música en la Educación-. http://ojs.uv.es/index/php/LEEME/index ISSN: 1575-9563. Editores: Universidad de Valencia y Jesús Tejada. Visibilidad de esta revista: SCOPUS, Emerging Sources Citation Index (Clarivate), EBSCO, CINDOC (CSIC), Citefactor, COPAC, Dialnet, DICE (CSIC), DOAJ, e-revistas (CSIC), EBSCO Premier, ERIH+, Gale Cengage Learning, IN-RECS, IRESIE, LATINDEX, MIAR, OCLC Worldcat, RESH, REDIB, RILM Core Journals, SUDOC, ULRICHS. Esta revista es de acceso libre mediante licencia Creative Commons $4.0 \mathrm{CC}$ by. Política de archivado: etiqueta verde SHERPA-ROMEO. 


\subsection{Instrumento}

Para llevar a cabo el análisis de los planes de estudio se ha utilizado una plantilla cualitativa elaborada expresamente por los investigadores del proyecto ALFA II-0448-A (Aróstegui, 2010), la cual fue debidamente validada, utilizada y actualizada entre los años 2006 y 2010. Dicha plantilla ha vuelto a ser revisada por un equipo de expertos en 2018 teniendo en cuenta la estructura, terminología y características concretas de los actuales planes de estudio recogidas en la Orden ECI/3858/2007 (Ministerio de Educación y Ciencia, 2007a). Las categorías que conforman la plantilla y a partir de les cuales se ha realizado el análisis comparativo de los planes de estudio se organizan y concretan de la siguiente manera:

- Bloque 1. Información general del plan de estudios:

1. Datos generales del plan de estudios: denominación de la titulación, competencias, objetivos, perfil de ingreso, perfil de egreso y evaluación de los conocimientos musicales.

2. Estructura del plan de estudios: duración, organización semestral, créditos ETCS de cada módulo y número de asignaturas.

3. Articulación plan de estudios: Relación entre la justificación del plan de estudios y sus objetivos, seriación y articulación horizontal y vertical de la estructura curricular, modelo educativo y tipo de énfasis didáctico o disciplinar de la formación.

- Bloque 2. Información específica musical. Las asignaturas se han distribuido en 4 apartados diferenciados:

1. Complementos para la Formación Disciplinar.

2. Aprendizaje y Enseñanza de las Materias.

3. Innovación Docente e Iniciación a la Investigación Educativa.

4. Prácticum, Prácticas y Trabajo Fin de Máster.

En cada uno de ellos se han establecido como categorías: curso, semestre, créditos ECTS, competencias, objetivos, contenidos, metodología y evaluación.

\subsection{Procedimiento}

Fase de recogida: Partiendo del Registro de Universidades, Centros y Títulos (RUCT) que ofrece de manera telemática el Gobierno de España, se han revisado todas las universidades españolas, públicas y privadas, que cuentan con la titulación de Máster en Profesorado, en un total de 68. Han sido recopiladas en una base de datos creada con el programa informático Microsoft Excel, organizadas por Comunidades Autónomas, especificando todas las sedes y centros adscritos. De estas, se han seleccionado solamente aquellas que impartían el MESM,

@Rosa María Serrano Pastor, Felipe Javier Zamorano Valenzuela y Cristina González Martín. The content of this article is the sole responsibility of the authors. The Revista Electrónica de LEEME and Universitat de València are not liable for any legal actions that may arise involving the article's content. Revista Electrónica de LEEME - Lista Electrónica Europea de Música en la Educación-. http://ojs.uv.es/index/php/LEEME/index ISSN: 1575-9563. Editores: Universidad de Valencia y Jesús Tejada. Visibilidad de esta revista: SCOPUS, Emerging Sources Citation Index (Clarivate), EBSCO, CINDOC (CSIC), Citefactor, COPAC, Dialnet, DICE (CSIC), DOAJ, e-revistas (CSIC), EBSCO Premier, ERIH+, Gale Cengage Learning, IN-RECS, IRESIE, LATINDEX, MIAR, OCLC Worldcat, RESH, REDIB, RILM Core Journals, SUDOC, ULRICHS. Esta revista es de acceso libre mediante licencia Creative Commons $4.0 \mathrm{CC}$ by. Política de archivado: etiqueta verde SHERPA-ROMEO. 


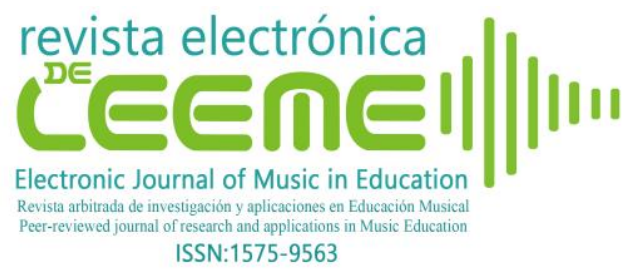

Rosa M. Serrano, Felipe Javier Zamorano y Cristina González Martín El Máster en Profesorado de Música: análisis de los planes de estudio desde la perspectiva de la sociedad y economía del conocimiento (Revista Electrónica de LEEME) Número 48, pp. 187-207 https://ojs.uv.es/index.php/LEEME/index

encontrando un total de 26 , de las cuales se han recopilado datos generales y específicos musicales en la plantilla anteriormente mencionada.

Fase de análisis: Estos datos se han organizado en 2 grandes bloques, que concuerdan con las categorías expuestas anteriormente y corresponden a una primera fase de análisis de carácter más descriptivo y de relación de datos de tipología general, y una segunda fase de análisis, más profunda, detallada y reflexiva sobre información de cada asignatura musical.

El primer bloque se ha organizado en 3 apartados: uno que ha recogido los datos generales de la titulación, para obtener una visión general del funcionamiento de cada máster. Otro que se ha centrado en el plan de estudios con una doble subdivisión entre los datos referentes a la duración y estructura del máster y aquellos referentes a las asignaturas del plan de estudios. Y, finalmente, un último apartado donde se han volcado aquellos datos relacionado con la articulación del plan de estudios, utilizando como base la relación entre todos los datos anteriormente obtenidos. Así mismo, un segundo bloque se ha centrado en analizar aquella información del módulo específico musical de cada plan de estudios. Este bloque se ha dividido en cuatro apartados diferenciados, correspondiendo con las asignaturas de cada módulo específico musical del plan de estudios: Complementos para la Formación Disciplinar (en adelante, CFD) para aquellas asignaturas referentes a aspectos curriculares; Aprendizaje y Enseñanza de las Materias (en adelante, AEM) para aquellas asignaturas relacionadas con elementos sobre la enseñanza-aprendizaje; Innovación Docente e Iniciación a la Investigación Educativa (en adelante, IDIIE) para las asignaturas con elementos de innovación e investigación, y del Prácticum en la especialización, Prácticas (en adelante, PR) y Trabajo Fin de Máster (adelante, TFM) para aquellas asignaturas relacionadas con ambos aspectos. De todos ellos, se ha recogido tanto datos descriptivos como información conceptual y procedimental que ha permitido establecer las tipologías que se presentan en los resultados.

A modo de síntesis, pueden verse en la Figura 1 las fases del proceso de investigación y el detalle de estas:

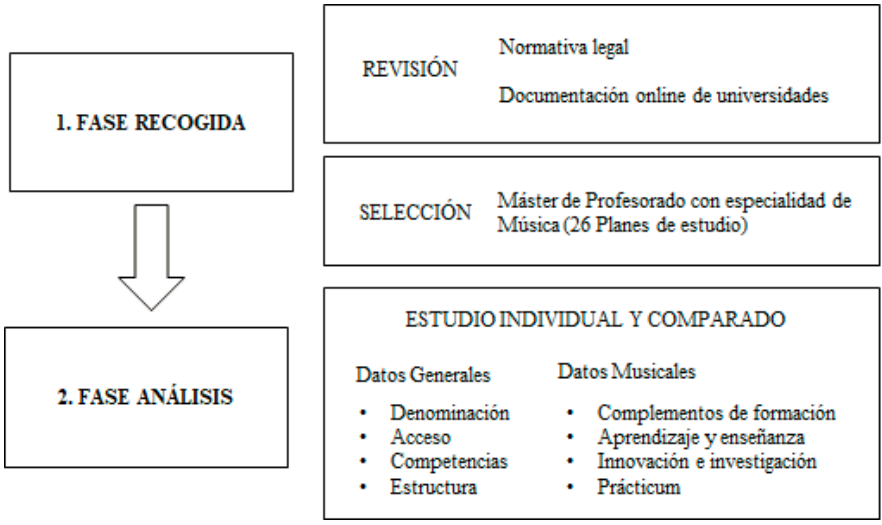

Figura 1. Relación entre fases y datos recopilados. Fuente: Elaboración propia

@Rosa María Serrano Pastor, Felipe Javier Zamorano Valenzuela y Cristina González Martín. The content of this article is the sole responsibility of the authors. The Revista Electrónica de LEEME and Universitat de València are not liable for any legal actions that may arise involving the article's content. Revista Electrónica de LEEME - Lista Electrónica Europea de Música en la Educación-. http://ojs.uv.es/index/php/LEEME/index ISSN: 1575-9563. Editores: Universidad de Valencia y Jesús Tejada. Visibilidad de esta revista: SCOPUS, Emerging Sources Citation Index (Clarivate), EBSCO, CINDOC (CSIC), Citefactor, COPAC, Dialnet, DICE (CSIC), DOAJ, e-revistas (CSIC), EBSCO Premier, ERIH+, Gale Cengage Learning, IN-RECS, IRESIE, LATINDEX, MIAR, OCLC Worldcat, RESH, REDIB, RILM Core Journals, SUDOC, ULRICHS. Esta revista es de acceso libre mediante licencia Creative Commons $4.0 \mathrm{CC}$ by. Política de archivado: etiqueta verde SHERPA-ROMEO. 


\section{Resultados}

La titulación del Máster en Educación Secundaria y Bachillerato tiene su origen en la necesidad de dar respuesta a la construcción del Espacio Europeo de Educación Superior (en adelante, EEES). El proceso iniciado en 1999 con la Declaración de Bolonia, conllevó cambios significativos en las normativas de las diferentes universidades europeas y, consecuentemente, en la estructura de sus titulaciones. En el caso español, la Ley Orgánica 4/2007 (Jefatura del Estado, 2007) y su concreción, el Real Decreto 1393/2007 (Ministerio de Educación y Ciencia, 2007b), asientan las bases para esta nueva estructuración y se reconoce la autonomía de cada universidad para la elaboración de su propio plan de estudios. Esta normativa promovió la diversificación curricular pero siempre cumpliendo la Orden ECI/3858/2007 (Ministerio de Educación y Ciencia, 2007a) que establece los requisitos para la verificación de dichos títulos universitarios oficiales. Teniendo en cuenta dicha legislación y la diversificación curricular en ella defendida, se procede a analizar de manera comparada cuáles han sido las bases comunes y diferenciadoras del MESM.

\subsection{Características generales}

La denominación del máster más utilizada por las diferentes universidades españolas (15 de las 26) es la de Máster Universitario en Profesorado (o en Formación del Profesorado) de ESO y Bachillerato, FP y Enseñanzas de Idiomas. Solo las universidades de Zaragoza y Murcia hacen mención explícita al profesorado de Enseñanzas Artísticas, lo que se valora positivamente por el reconocimiento expreso al área que ello conlleva. La denominación de la especialidad en todas ellas es de "Especialidad Música", salvo contadas excepciones que ofrecen la "Especialidad de Artes" o "Música y Danza".

En relación con el desarrollo competencial del alumnado, la normativa especifica 11 competencias, si bien se observa una gran variación en el foco de atención en unas u otras dependiendo del plan de estudios. Algunas universidades (Zaragoza, Valencia, Las Palmas o Santiago de Compostela) ponen su hincapié en las relacionadas con la formación pedagógica y didáctica, mientras otras (Barcelona y Alicante) resaltan en primer término el conocimiento de los contenidos curriculares. Son varias las que resaltan el conocimiento de la normativa institucional y, en casos contados, la innovación e investigación en el aula, la atención a la diversidad y la tutoría, la educación emocional y resolución de conflictos. La apertura a estas últimas temáticas ofrece un enriquecimiento a la titulación que debería ser tenido en cuenta por todas las instituciones.

En lo que respecta a la estructura del Máster, en todo el territorio español está organizado en un solo curso académico, acogiéndose al formato del EEES de 4 años para el Grado y 1 año para el Máster. Dicho curso, por norma general, está estructurado en dos

@Rosa María Serrano Pastor, Felipe Javier Zamorano Valenzuela y Cristina González Martín. The content of this article is the sole responsibility of the authors. The Revista Electrónica de LEEME and Universitat de València are not liable for any legal actions that may arise involving the article's content. Revista Electrónica de LEEME - Lista Electrónica Europea de Música en la Educación-. http://ojs.uv.es/index/php/LEEME/index ISSN: 1575-9563. Editores: Universidad de Valencia y Jesús Tejada. Visibilidad de esta revista: SCOPUS, Emerging Sources Citation Index (Clarivate), EBSCO, CINDOC (CSIC), Citefactor, COPAC, Dialnet, DICE (CSIC), DOAJ, e-revistas (CSIC), EBSCO Premier, ERIH+, Gale Cengage Learning, IN-RECS, IRESIE, LATINDEX, MIAR, OCLC Worldcat, RESH, REDIB, RILM Core Journals, SUDOC, ULRICHS. Esta revista es de acceso libre mediante licencia Creative Commons $4.0 \mathrm{CC}$ by. Política de archivado: etiqueta verde SHERPA-ROMEO. 
semestres, implementando en el primero de ellos las asignaturas pertenecientes al Módulo Genérico. Se observan algunas excepciones en ciertas universidades como la de Valencia que presentan una organización anual y otras que combinan asignaturas semestrales con anuales.

Cumpliendo con la normativa, el número total de créditos con los que cuenta el Máster en todas las universidades es de 60 créditos ECTS los cuales son repartidos de manera compensada entre ambos semestres. Como norma general, los planes de estudio ofrecen en torno a 11 materias distribuidas entre los semestres, aunque encontramos algunos extremos como el caso de las universidades de Salamanca con 16 asignaturas o la Autónoma de Madrid con 8 .

En relación al reparto de créditos ECTS entre créditos Obligatorios, Optativos y Prácticum, se corresponde respectivamente y por norma general con los Módulos Genérico, Específico y Prácticum estructurados en la normativa. En ella, se especifica un mínimo de 12, 24 y 16 créditos ECTS respectivamente en los diferentes módulos, dejando 8 créditos ECTS para la distribución por parte de cada universidad. Se encuentra una mayor tendencia de peso en créditos optativos, especialmente destinado al Módulo Específico Musical, con varias universidades que ofrecen 30 créditos ECTS, frente a los 12 créditos ECTS de asignaturas obligatorias de carácter genérico que comparten con todas las especialidades. En el caso contrario, la Universidad de Oviedo destina 38 créditos ECTS a asignaturas obligatorias frente a los únicamente 3 créditos ECTS de optativas, lo que muestra la gran variabilidad dentro del territorio español.

\subsection{Presencia de las materias específicas de Educación Musical}

El análisis de los datos muestra una presencia diferente de las materias específicas, como refleja la siguiente tabla:

Tabla 2. Comparativa de la presencia de cada materia de formación específica

\begin{tabular}{|c|c|c|c|c|}
\hline & \multicolumn{3}{|c|}{ MATERIAS } & MÓDULO \\
\hline & CFD & AEM & IDIIE & PR \\
\hline $\begin{array}{l}\mathrm{N}^{\circ} \mathrm{DE} \\
\text { ASIGNATURAS }\end{array}$ & $\begin{array}{c}1 \text { asignatura }(14 u) \\
2 \text { asignaturas }(10 u) \\
3 \text { asignaturas }(2 u)\end{array}$ & $\begin{array}{l}0 \text { asignaturas }(1 \mathrm{u})^{*} \\
1 \text { asignatura }(11 \mathrm{u}) \\
2 \text { asignaturas }(5 \mathrm{u}) \\
3 \text { asignaturas }(7 \mathrm{u}) \\
5 \text { asignaturas }(1 \mathrm{u})\end{array}$ & $\begin{array}{l}1 \text { asignatura }(21 u) \\
2 \text { asignaturas }(4 u) \\
3 \text { asignaturas }(1 u)\end{array}$ & $\begin{array}{l}2 \text { asignaturas }(19 u) \\
3 \text { asignaturas }(6 u) \\
4 \text { asignaturas }(1 u)\end{array}$ \\
\hline SEMESTRE & $\begin{array}{c}\text { 1r semestre }(11 u) \\
\text { 2o semestre }(6 u) \\
\text { Anual }(7 \mathrm{u}) \\
\left(2^{\text {o }} \text { u. no se concretan }\right)\end{array}$ & $\begin{array}{c}\text { 1r semestre }(6 u) \\
2^{\circ} \text { semestre }(6 u) \\
\text { Anual }(12 u) \\
\left(2^{o} \text { u no concretan }\right)\end{array}$ & $\begin{array}{c}\text { 1r semestre }(6 u) \\
2^{\circ} \text { semestre }(16 u) \\
\text { Anual }(4 u)\end{array}$ & $\begin{array}{l}2^{\circ} \text { semestre }(12 u) \\
\text { Anual }(14 u)\end{array}$ \\
\hline $\begin{array}{l}\text { CREDITOS } \\
\text { TOTALES }\end{array}$ & $\begin{array}{l}\text { Entre } 5 \text { y } 12 \text { créditos. } \\
\text { Media: } 7.3 \text { créditos }\end{array}$ & $\begin{array}{l}\text { Entre } 6 \text { y } 18 \text { créditos. } \\
\text { Media: } 12.0 \text { créditos }\end{array}$ & $\begin{array}{l}\text { Entre } 2 \text { y } 12 \text { créditos } \\
\text { Media: } 5.6 \text { créditos }\end{array}$ & $\begin{array}{l}\text { Entre } 16 \text { y } 24 \text { créditos } \\
\text { Media: } 17.7 \text { créditos }\end{array}$ \\
\hline
\end{tabular}

@Rosa María Serrano Pastor, Felipe Javier Zamorano Valenzuela y Cristina González Martín. The content of this article is the sole responsibility of the authors. The Revista Electrónica de LEEME and Universitat de València are not liable for any legal actions that may arise involving the article's content. Revista Electrónica de LEEME - Lista Electrónica Europea de Música en la Educación-. http://ojs.uv.es/index/php/LEEME/index ISSN: 1575-9563. Editores: Universidad de Valencia y Jesús Tejada. Visibilidad de esta revista: SCOPUS, Emerging Sources Citation Index (Clarivate), EBSCO, CINDOC (CSIC), Citefactor, COPAC, Dialnet, DICE (CSIC), DOAJ, e-revistas (CSIC), EBSCO Premier, ERIH+, Gale Cengage Learning, IN-RECS, IRESIE, LATINDEX, MIAR, OCLC Worldcat, RESH, REDIB, RILM Core Journals, SUDOC, ULRICHS. Esta revista es de acceso libre mediante licencia Creative Commons $4.0 \mathrm{CC}$ by. Política de archivado: etiqueta verde SHERPA-ROMEO. 
PRESENCIA EN EL Entre 8\% y un 20\%

Entre $10 \%$ y $29 \%$

Entre $3.33 \%$ y $20 \%$

$26.6 \%$ y $40 \%$ MÁSTER

Media: $12.2 \%$

Media: $20.0 \%$

Media: $9.3 \%$

Media: $29.6 \%$

* Una universidad ofrece estas asignaturas de manera general para todas las especialidades

Fuente: Elaboración propia

Realizando un análisis comparativo de la información presentada en la tabla anterior, las materias que se priorizan son PR y TFM con una media de dedicación de casi el 30\% del total del máster, llegando a ocupar el $40 \%$ en el caso de la Universidad Europea. En la mayoría de los planes, se dividen únicamente en dos asignaturas. La segunda materia con mayor reconocimiento horario es AEM, con una dedicación media de $20.4 \%$, llegando en algún caso hasta el 29\%. En tercer lugar, se encuentran las asignaturas pertenecientes a CFD para finalizar con un $9.3 \%$ en el caso de IDIIE.

En cuanto a la variabilidad entre universidades es destacable la diversidad encontrada en AEM, tanto en el número de asignaturas como de créditos ECTS asignados y en su reparto temporal a lo largo del curso. El TFM muestra la mayor uniformidad en todas las universidades, donde 25 de los 26 planes de estudio le asignan 6 créditos y 19 de ellos lo ofrecen en el segundo semestre por considerar que da cierre al máster.

En lo que respecta a CFD, tiene una mayor presencia en el primer semestre (11 planes de estudio), al contrario que IDIIE. Estos datos muestran cierta tendencia a la modalidad consecutiva, en el que se trabaja previamente la formación disciplinar para luego llegar a la didáctica y a la innovación. Pese a ello, algunas universidades, como las de Valencia y Oviedo, presentan una clara apuesta hacia la modalidad simultánea de formación. Esto lo consiguen ofreciendo asignaturas anuales y combinando asignaturas entre el primer y segundo semestre, con las posibilidades que esta distribución ofrece para la trasferencia de conocimiento entre asignaturas.

\subsection{Focos temáticos}

Además del análisis comparativo anterior, resulta de interés examinar las temáticas sobre las que versan estas materias en cada una de las universidades para conocer en profundidad la direccionalidad de la formación en los planes de estudio.

\subsubsection{Materia CFD}

De las 40 asignaturas ofertadas se encuentran 27 títulos diferentes, si bien analizando su contenido se observan concepciones comunes que permiten estructurarlas en 4 tipologías:

- Tipología 1: Contenidos musicales de Educación Secundaria y Bachillerato. Recoge el conocimiento de los contenidos del currículum. Destaca la

@Rosa María Serrano Pastor, Felipe Javier Zamorano Valenzuela y Cristina González Martín. The content of this article is the sole responsibility of the authors. The Revista Electrónica de LEEME and Universitat de València are not liable for any legal actions that may arise involving the article's content. Revista Electrónica de LEEME - Lista Electrónica Europea de Música en la Educación-. http://ojs.uv.es/index/php/LEEME/index ISSN: 1575-9563. Editores: Universidad de Valencia y Jesús Tejada. Visibilidad de esta revista: SCOPUS, Emerging Sources Citation Index (Clarivate), EBSCO, CINDOC (CSIC), Citefactor, COPAC, Dialnet, DICE (CSIC), DOAJ, e-revistas (CSIC), EBSCO Premier, ERIH+, Gale Cengage Learning, IN-RECS, IRESIE, LATINDEX, MIAR, OCLC Worldcat, RESH, REDIB, RILM Core Journals, SUDOC, ULRICHS. Esta revista es de acceso libre mediante licencia Creative Commons $4.0 \mathrm{CC}$ by. Política de archivado: etiqueta verde SHERPA-ROMEO. 
formación en repertorio y análisis de audición, educación vocal y foniatría, repertorio y dirección coral e instrumental, expresión corporal y danza, composición y arreglo de partituras, música y medios audiovisuales, historia de la música, música y sociedad, música y fenómenos actuales. Además, el profesorado también debe conocer los objetivos, competencias, recursos y evaluación del currículum.

- Tipología 2: Bases teóricas del currículum de Educación Musical. Añade a la anterior ciertas bases teóricas relacionadas con la Educación Musical de corte psicopedagógico, sociológico, psicológico y de desarrollo musical, legislativo y de historia de la Educación Musical, evaluativo, del perfil del profesorado de música y en algunos casos investigador.

- Tipología 3: Fundamentos de la didáctica musical. Incluye aspectos didácticos como aprender a hacer unidades didácticas, programaciones, conocer metodologías de enseñanza-aprendizaje musical (desde una perspectiva teórica), así como el conocimiento teórico de las corrientes pedagógicas musicales del siglo XX y XXI. Se aborda el currículo desde un enfoque más procedimental y no tan conceptual, por eso también están dedicadas a la selección y elaboración de materiales (partituras gráficas, canciones, instrumentaciones...) y diseño (sin aplicación) de ejercicios prácticos.

- Tipología 4: Competencias para el aprendizaje musical para la SyEC. Persigue no sólo dominar el contenido sino relacionarlo con el entorno y el contexto en el que se sitúa, o con la sociedad actual. Trata temas como música y contexto, tecnología, proyectos de mejora, proyectos interdisciplinares, y el papel de la diversidad y la multiculturalidad en el ámbito musical.

Aunque a grandes rasgos los contenidos tratados en cada asignatura analizada se pueden clasificar en una de estas cuatro tipologías, debe comentarse que también se encuentran asignaturas que combinan diferentes tipologías de las mencionadas. De hecho, haciendo un análisis general, la tipología de asignatura predominante (aproximadamente la mitad de las analizadas, bien de manera única o combinada con otras tipologías) es la tipología 1 (18 planes de estudio), como en las universidades de Alicante y Sevilla, seguida de la tipología 3 (12 planes de estudio). Se encuentra, por ello, un mayor peso en los contenidos específicos musicales y en aspectos didácticos y metodológicos musicales, pero únicamente desde la perspectiva teórica que poco puede ofrecer al enriquecimiento docente. En menor medida, aparece la tipología 2 ( 7 planes de estudio) y, finalmente, la 4 (9 planes de estudio), que aporta al profesorado el conocimiento musical para prepararlo para la SyEC, como en las universidades de Islas Baleares o Jaume I.

@Rosa María Serrano Pastor, Felipe Javier Zamorano Valenzuela y Cristina González Martín. The content of this article is the sole responsibility of the authors. The Revista Electrónica de LEEME and Universitat de València are not liable for any legal actions that may arise involving the article's content. Revista Electrónica de LEEME - Lista Electrónica Europea de Música en la Educación-. http://ojs.uv.es/index/php/LEEME/index ISSN: 1575-9563. Editores: Universidad de Valencia y Jesús Tejada. Visibilidad de esta revista: SCOPUS, Emerging Sources Citation Index (Clarivate), EBSCO, CINDOC (CSIC), Citefactor, COPAC, Dialnet, DICE (CSIC), DOAJ, e-revistas (CSIC), EBSCO Premier, ERIH+, Gale Cengage Learning, IN-RECS, IRESIE, LATINDEX, MIAR, OCLC Worldcat, RESH, REDIB, RILM Core Journals, SUDOC, ULRICHS. Esta revista es de acceso libre mediante licencia Creative Commons $4.0 \mathrm{CC}$ by. Política de archivado: etiqueta verde SHERPA-ROMEO. 


\subsubsection{Materia AEM}

En las 50 asignaturas ofertadas, se encuentra una variedad de 33 títulos que conducen a temáticas recurrentes como "aprendizaje y enseñanza" (14 asignaturas) o "didáctica" (9 asignaturas). En menor medida, se observa otros como "evaluación", "metodología" o "medios audiovisuales". El enfoque de esta materia es eminentemente práctico frente a la anterior CFD, donde se priorizan los contenidos conceptuales. Analizando el contenido de estas asignaturas, pueden ser organizadas en cuatro tipologías:

- Tipología 1: Formación en contenido musical específico y su didáctica. Combina la formación disciplinar en música y su aplicación didáctica, realizando una revisión teórica de fundamentos para luego pasar a la práctica. Los contenidos más frecuentes son: música del mundo, nuevas tecnologías, práctica instrumental y vocal y su dirección, creación, escucha, historia de la música, danza y expresión corporal, y elementos del lenguaje musical.

- Tipología 2: Enseñanza y aprendizaje de la música. Trata aspectos relacionados directamente con la didáctica de la música. Algunas temáticas son recurrentes en la mayoría de las asignaturas, tales como metodologías musicales del siglo XX y XXI, fundamentos de la didáctica de la música, elaboración de procesos formativos, evaluación, diseño de unidades didácticas y materiales.

- Tipología 3: Formación en didáctica de la música con carácter competencial. Aunque trata los aspectos relacionados con la didáctica de la música, difiere de la anterior en su carácter competencial. Es decir, se busca que el profesorado conecte los recursos y conocimientos con aspectos que van más allá de la didáctica de la música propiamente dicha, como la atención a la diversidad, la interdisciplinariedad, la resolución de conflictos en el aula, la función y opinión crítica docente, la innovación docente y en algún caso la investigación.

- Tipología 4: Recursos para el profesorado de música. Centrada en recursos y actividades directamente aplicables al aula, planteados por el profesorado (como en las universidades de Salamanca y València) o creados y elaborados por los propios estudiantes (como en las universidades de Illes Balears, Alicante y Zaragoza), siendo este último paso valorado positivamente. Los materiales permiten trabajar contenidos musicales del currículo (audición, interpretación y creación) o recursos concretos (audiovisuales, bibliográficos, tradicionales...).

Si se analiza su frecuencia, la que más predomina es la tipología 2 (20 asignaturas) centrada directamente en la didáctica. De ello se puede plantear si el estudiante tiene la suficiente capacidad para relacionar lo trabajado en la materia CFD con la didáctica aquí ofrecida. Le sigue en frecuencia la tipología 1 (14 asignaturas), que relaciona explícitamente los

@Rosa María Serrano Pastor, Felipe Javier Zamorano Valenzuela y Cristina González Martín. The content of this article is the sole responsibility of the authors. The Revista Electrónica de LEEME and Universitat de València are not liable for any legal actions that may arise involving the article's content. Revista Electrónica de LEEME - Lista Electrónica Europea de Música en la Educación-. http://ojs.uv.es/index/php/LEEME/index ISSN: 1575-9563. Editores: Universidad de Valencia y Jesús Tejada. Visibilidad de esta revista: SCOPUS, Emerging Sources Citation Index (Clarivate), EBSCO, CINDOC (CSIC), Citefactor, COPAC, Dialnet, DICE (CSIC), DOAJ, e-revistas (CSIC), EBSCO Premier, ERIH+, Gale Cengage Learning, IN-RECS, IRESIE, LATINDEX, MIAR, OCLC Worldcat, RESH, REDIB, RILM Core Journals, SUDOC, ULRICHS. Esta revista es de acceso libre mediante licencia Creative Commons $4.0 \mathrm{CC}$ by. Política de archivado: etiqueta verde SHERPA-ROMEO. 


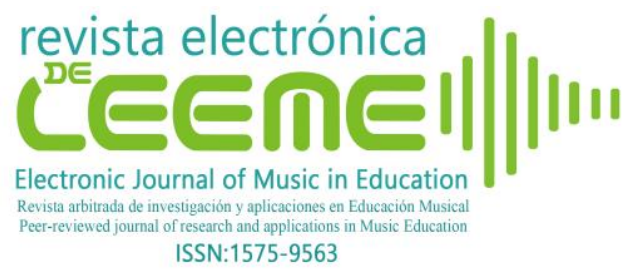

Rosa M. Serrano, Felipe Javier Zamorano y Cristina González Martín El Máster en Profesorado de Música: análisis de los planes de estudio desde la perspectiva de la sociedad y economía del conocimiento (Revista Electrónica de LEEME) Número 48, pp. 187-207 https://ojs.uv.es/index.php/LEEME/index

contenidos con su didáctica, como sucede en las universidades de Valladolid o Granada, enriqueciendo la formación didáctico-musical del alumnado. En menor medida, se encuentra la tipología 3 y 4, si bien hay cierta tendencia a ofrecer actividades "receta" que aplicar directamente sin el enfoque reflexivo y creativo que la SyEC demanda y que se considera necesario. De las 50 asignaturas, la mayoría (30 asignaturas) pueden relacionarse con una de las tipologías; el resto son el resultado de la combinación de dos tipologías de asignaturas. La tipología que aparece menos combinada es la 2 , mientras que la 3 es la más combinada.

\subsubsection{Materia IDIIE}

Puede encontrarse un total de 32 asignaturas con títulos muy similares que hacen referencia tanto a la investigación como a la innovación. Respecto al foco genérico o musical que poseen estas asignaturas, se observa cierta diversidad, aunque en su mayoría (20 asignaturas) tienden a cumplir con su foco musical. En contraste, se encuentran asignaturas con un foco genérico, bien por ser asignaturas que no se ofrecen en la especialidad o que se comparte una parte de la misma con otras especialidades, bien por no especificar contenidos musicales, aunque estén dentro de la especialidad. Realizando un análisis de los contenidos, esta materia puede ser dividida en las siguientes tipologías:

- Tipología 1: Fundamentos de la innovación. Resalta la disposición reflexiva del profesorado de música como punto de partida para la transformación social desde los proyectos musicales, el análisis de buenas prácticas basado en indicadores de calidad y la evaluación de proyectos de innovación existentes.

- Tipología 2: La innovación como metodología. Pone el foco en el aprendizaje y enseñanza a través de las TIC. En menor medida se vincula a una nueva mirada de las metodologías musicales del siglo XXI, a la composición, creación y edición de arreglos musicales, y a la improvisación. En algunos casos también se propone la interdisciplinariedad.

- Tipología 3: Aprendizaje funcional de la investigación. Se centra en la estructura de los proyectos de investigación: revisión de paradigmas, métodos de recogida, estrategias de análisis, revisión de literatura y elaboración del trabajo de investigación. En algunos casos, resalta una mirada funcional de la investigación respecto al mismo máster, en donde todo conocimiento investigativo adquirido servirá para la producción del TFM (como en las universidades Católica de Valencia, Oviedo, Valladolid y Complutense de Madrid) o del Prácticum (como en las universidades de Granada y Oviedo).

- Tipología 4: La investigación en contexto. Ofrece vinculación entre la investigación y la docencia reflexiva. En menor medida, se observan propuestas que vinculan explícitamente la investigación docente, bien a problemáticas socioculturales como la interculturalidad, equidad, educación en

@Rosa María Serrano Pastor, Felipe Javier Zamorano Valenzuela y Cristina González Martín. The content of this article is the sole responsibility of the authors. The Revista Electrónica de LEEME and Universitat de València are not liable for any legal actions that may arise involving the article's content. Revista Electrónica de LEEME - Lista Electrónica Europea de Música en la Educación-. http://ojs.uv.es/index/php/LEEME/index ISSN: 1575-9563. Editores: Universidad de Valencia y Jesús Tejada. Visibilidad de esta revista: SCOPUS, Emerging Sources Citation Index (Clarivate), EBSCO, CINDOC (CSIC), Citefactor, COPAC, Dialnet, DICE (CSIC), DOAJ, e-revistas (CSIC), EBSCO Premier, ERIH+, Gale Cengage Learning, IN-RECS, IRESIE, LATINDEX, MIAR, OCLC Worldcat, RESH, REDIB, RILM Core Journals, SUDOC, ULRICHS. Esta revista es de acceso libre mediante licencia Creative Commons $4.0 \mathrm{CC}$ by. Política de archivado: etiqueta verde SHERPA-ROMEO. 
valores y la significación social del currículum, bien a perspectivas investigativas de investigación histórica, sistemática o musicológica.

En términos generales las temáticas se equilibran entre los bloques de innovación e investigación ( 23 planes de estudio), si bien encontramos varios casos que se centran en uno de ellos. La tipología más frecuente es la tipología 3 (22 planes de estudio). Le sigue la tipología 2, que se entiende como parte del bloque de contenidos que aluden a la innovación dentro de la IDIIE. Estas dos tipologías tienen un carácter altamente práctico en tanto guían al alumnado, a través de estructuras de los trabajos de investigación y metodologías innovadoras, hacia la concreción del TFM y la adquisición de herramientas novedosas, respectivamente.

\subsubsection{Materia PR y TFM}

Hay un total de 60 asignaturas con títulos muy similares tanto en el caso de PR, dividiendo en grados en algunos casos, y TFM. El foco en ambas materias es de carácter genérico, pues no se mencionan tareas relacionadas con la música en las guías docentes, aunque su aplicación en la mayoría de los casos es, acertadamente, en el campo musical. En el caso del PR, la concepción en todos los planes se concibe como un espacio para conocer de manera directa el centro educativo y el trabajo docente, así como acercar la teoría a la práctica. Metodológicamente muestran una división similar que progresa de la observación a la planificación e intervención en el aula, solicitando como producto final un informe que sintetice la experiencia y reflexión en los centros. Para ello, se cuenta con una doble tutorización: del docente universitario y del docente en el centro educativo.

En cuanto al TFM se concibe como un trabajo escrito que debe integrar de manera reflexiva todos los contenidos y/o competencias desarrolladas en el máster, así como demostrar las capacidades de planificar, resolver problemas e interpretar resultados. Las tipologías encontradas en estas materias son las siguientes:

- Tipología 1: Adecuación al contexto escolar. Recoge aquellas asignaturas de PR que ponen su énfasis en conocer y adecuar su actuación, planificación, intervención y evaluación a los requerimientos del Centro escolar. En el caso del TFM, se centra en el diseño de programaciones o materiales didácticos. En casos muy específicos, como la Universidad Internacional de Valencia, se propone la posibilidad de crear materiales didácticos para la atención a la diversidad.

- Tipología 2: Espacio para la innovación e investigación. Incluye el concepto de innovación y/o investigación en su propuesta. En el TFM, se entiende como la construcción incipiente de conocimientos sobre la indagación a través de la realización de una pequeña investigación o proyecto de innovación, en relación

@Rosa María Serrano Pastor, Felipe Javier Zamorano Valenzuela y Cristina González Martín. The content of this article is the sole responsibility of the authors. The Revista Electrónica de LEEME and Universitat de València are not liable for any legal actions that may arise involving the article's content. Revista Electrónica de LEEME - Lista Electrónica Europea de Música en la Educación-. http://ojs.uv.es/index/php/LEEME/index ISSN: 1575-9563. Editores: Universidad de Valencia y Jesús Tejada. Visibilidad de esta revista: SCOPUS, Emerging Sources Citation Index (Clarivate), EBSCO, CINDOC (CSIC), Citefactor, COPAC, Dialnet, DICE (CSIC), DOAJ, e-revistas (CSIC), EBSCO Premier, ERIH+, Gale Cengage Learning, IN-RECS, IRESIE, LATINDEX, MIAR, OCLC Worldcat, RESH, REDIB, RILM Core Journals, SUDOC, ULRICHS. Esta revista es de acceso libre mediante licencia Creative Commons $4.0 \mathrm{CC}$ by. Política de archivado: etiqueta verde SHERPA-ROMEO. 


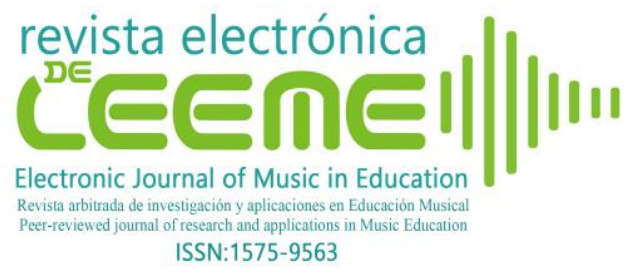

Rosa M. Serrano, Felipe Javier Zamorano y Cristina González Martín El Máster en Profesorado de Música: análisis de los planes de estudio desde la perspectiva de la sociedad y economía del conocimiento (Revista Electrónica de LEEME) Número 48, pp. 187-207 https://ojs.uv.es/index.php/LEEME/index

a las observaciones del PR o temáticas afines y con posibilidades de aplicación directa en dicho PR.

Analizando su frecuencia, en el caso del PR la que predomina es la tipología 1 (18 planes de estudio) frente a la tipología 2 ( 8 planes de estudio), siendo esta última la que ofrece un mayor acercamiento a los requerimientos de la SyEC. En el caso del TFM, los planes de estudio tienden hacia la tipología 2, con 18 planes de estudio que ofrecen la posibilidad de iniciarse en la investigación y 13 en la innovación, como en las universidades de Oviedo y La Coruña.

\section{Discusión y conclusiones}

La formación del profesorado de Música de Secundaria y Bachillerato en España encuentra diferentes propuestas formativas bajo un paraguas legislativo único de máster de modalidad consecutiva (de un año con una formación previa musical de un mínimo de 4 años) y una estructura básica de competencias, módulos y créditos mínimos. Esta estructura legislativa obstaculiza de inicio ciertos planteamientos que la SyEC demanda debido a la segmentación en módulos que establece. Esto significa que la división, por un lado, dificulta la interdisciplinariedad y el trabajo colaborativo y, por otro lado, da pie al mantenimiento de una tradición academicista con excesivo énfasis en los complementos disciplinares. Dentro de este marco, las propuestas de cada máster difieren tanto en cuestiones cuantitativas de distribución, cantidad de créditos y asignaturas por módulo y materia como, y especialmente relevante, en objetivos y contenidos propuestos. Estas cuestiones revelan ciertas orientaciones formativas que sirven de fundamento a una formación del profesorado muy dispar a lo largo del territorio. Si bien existe una mayor tendencia, más de la deseable, a continuar con dicha tradición academicista, ya planteada por autores como Liston y Zeichner (1997) o Ballantyne (2007), también se encuentran ejemplos positivos que apuestan por una formación simultánea dentro del máster. Esto último significa que algunos planes de estudio promueven fuertemente la didáctica y el trabajo interdisciplinar, donde la reflexión, innovación, investigación y propuestas creativas del alumnado son el eje de diferentes asignaturas interrelacionadas, aspectos resaltados como efectivos (Ballantyne, 2007; Liston y Zeichner, 1997).

Profundizando con más detenimiento en cada uno de estos aspectos, los planes de estudio del MESM tienden a la modalidad consecutiva, con un inicio centrado en las asignaturas genéricas y de formación disciplinar musical y un segundo semestre con asignaturas que promueven el conocimiento didáctico. Todo ello dificulta la interdisciplinariedad, apenas ofertada en la titulación (Marcelo, 2001), el desarrollo de una reflexividad colectiva (Torres, 2006) y una mirada integrada de la enseñanza desde los diversos conocimientos escolares y los problemas pedagógicos y educativos generales que demanda la SyEC. Asimismo, abre el debate sobre cuál debería ser el foco y formato de la formación del profesorado de música, teniendo en cuenta que la preparación previa de los estudiantes "es muy variada y normalmente carece de

@Rosa María Serrano Pastor, Felipe Javier Zamorano Valenzuela y Cristina González Martín. The content of this article is the sole responsibility of the authors. The Revista Electrónica de LEEME and Universitat de València are not liable for any legal actions that may arise involving the article's content. Revista Electrónica de LEEME - Lista Electrónica Europea de Música en la Educación-. http://ojs.uv.es/index/php/LEEME/index ISSN: 1575-9563. Editores: Universidad de Valencia y Jesús Tejada. Visibilidad de esta revista: SCOPUS, Emerging Sources Citation Index (Clarivate), EBSCO, CINDOC (CSIC), Citefactor, COPAC, Dialnet, DICE (CSIC), DOAJ, e-revistas (CSIC), EBSCO Premier, ERIH+, Gale Cengage Learning, IN-RECS, IRESIE, LATINDEX, MIAR, OCLC Worldcat, RESH, REDIB, RILM Core Journals, SUDOC, ULRICHS. Esta revista es de acceso libre mediante licencia Creative Commons $4.0 \mathrm{CC}$ by. Política de archivado: etiqueta verde SHERPA-ROMEO. 


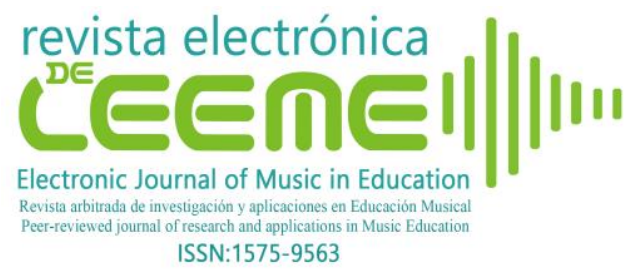

Rosa M. Serrano, Felipe Javier Zamorano y Cristina González Martín El Máster en Profesorado de Música: análisis de los planes de estudio desde la perspectiva de la sociedad y economía del conocimiento (Revista Electrónica de LEEME) Número 48, pp. 187-207 https://ojs.uv.es/index.php/LEEME/index

una formación pedagógica y didáctica" (Lucato, 2001, p.6) y la extensión del máster es de sólo un año, la cual probablemente es insuficiente (Checa, 2004).

El análisis del módulo específico musical y prácticum muestra una tendencia al conocimiento del contenido curricular y normativo sin visión crítica de mejora. Esto significa que se promueve tanto la réplica y perpetuación de los modelos didácticos existentes a través de una batería de materiales y recursos de aplicación directa como el conocimiento metodológico eminentemente teórico y, por tanto, poco funcional. Ambos aspectos revelan la predisposición a construir capacidades y recursos que buscan la adaptación y aplicación en la escuela, y en un último caso, la innovación. Si bien su presencia es mínima, la materia IDIIE parece ofrecer espacios tanto para la reflexión y creación en torno a la innovación como para el trabajo didáctico basado en las TIC. Hay que señalar que es una materia que ofrece, en algunos planes de estudio, interrelación con el Prácticum y TFM, coincidiendo con las asignaturas más novedosas con respecto al antiguo Certificado de Aptitud Pedagógica (CAP), lo que parece indicar cierta dicotomía entre un anclaje en la formación academicista tradicional y una clara apuesta de algunas universidades por modelos reflexivos, actualizados y creativos.

Desde el punto de vista de los modelos didácticos (Jorquera, 2010) y su comprensión implícita de la escuela como espacio cierto capaz de objetivarse, o como un espacio problemático altamente subjetivo e incierto (Zeichner, 1983), se observa que el MESM promueve la certidumbre a través de: 1) el modelo académico y su objetivación del conocimiento musical, 2) el modelo práctico y su reparo en el ejercicio musical por sí solo, 3) el modelo comunicativo-lúdico y su foco en la motivación del estudiante. De esta manera, el modelo complejo, que utiliza la investigación en la práctica para reorganizar y diversificar la experiencia musical, queda en un nivel superficial e instrumental, tanto por la minimización de la innovación como por la concepción que se tiene del TFM.

Por todo ello, los planes de estudio deben ser reevaluados por los directivos y académicos tomando en cuenta la legislación actual, pero aventurándose a diseñar espacios reflexivos y críticos donde se promuevan las capacidades que demanda la SyEC. Esto significa que es necesario que la formación del profesorado de educación musical no quede únicamente anclada a tradiciones y modelos determinados (Aróstegui y Cisneros-Cohernour, 2010; Jorquera, 2010); sino que ofrezca la posibilidad de conocer la diversidad del mundo educativo general y musical, y de desarrollar cierta disposición crítica a la tradición (Jorgensen, 2003). La reflexividad colegiada (Torres, 2006), el pensamiento creativo (Scheib, 2006), el emprendimiento y la interdisciplinariedad (Marcelo, 2001), en búsqueda de tareas competenciales significativas para el alumnado frente a la mera reproducción de actividades prediseñadas, son alternativas ofrecidas por algunas universidades que se valoran positivamente. Asimismo, la integración tecnológica y la innovación (Aróstegui, 2017) y la sensibilidad hacia las problemáticas socioculturales que rodean a la escuela (Zeichner, 2005) se consideran

@Rosa María Serrano Pastor, Felipe Javier Zamorano Valenzuela y Cristina González Martín. The content of this article is the sole responsibility of the authors. The Revista Electrónica de LEEME and Universitat de València are not liable for any legal actions that may arise involving the article's content. Revista Electrónica de LEEME - Lista Electrónica Europea de Música en la Educación-. http://ojs.uv.es/index/php/LEEME/index ISSN: 1575-9563. Editores: Universidad de Valencia y Jesús Tejada. Visibilidad de esta revista: SCOPUS, Emerging Sources Citation Index (Clarivate), EBSCO, CINDOC (CSIC), Citefactor, COPAC, Dialnet, DICE (CSIC), DOAJ, e-revistas (CSIC), EBSCO Premier, ERIH+, Gale Cengage Learning, IN-RECS, IRESIE, LATINDEX, MIAR, OCLC Worldcat, RESH, REDIB, RILM Core Journals, SUDOC, ULRICHS. Esta revista es de acceso libre mediante licencia Creative Commons $4.0 \mathrm{CC}$ by. Política de archivado: etiqueta verde SHERPA-ROMEO. 
elementos claves que ciertos planes de estudio de MESM recogen para dar respuesta a la SyEC y cuya generalización al resto de planes sería deseable.

\section{Financiación y agradecimientos}

Este artículo es parte del Proyecto de Investigación Formación de Profesorado y Música en la Sociedad y la Economía del Conocimiento (I+D EDU2017-84782), correspondiente al Programa Estatal de Fomento de la Investigación Científica y Técnica de Excelencia del Ministerio de Economía y Competitividad del Gobierno de España.

\section{Referencias}

Aróstegui, J.L. (2010). Formación del profesorado de música: planes de estudio en Europa y América Latina. Profesorado. Revista de Currículum y Formación del Profesorado, 14(2), 3-7. Recuperado de: https://recyt.fecyt.es/index.php/profesorado/article/

Aróstegui, J.L. (2011). Por un currículo contrahegemónico: de la educación musical a la música educativa. Revista da ABEM, 19(25), 19-29. Recuperado de: http://www.abemeducacaomusical.com.br/revistas/revistaabem/index.php/revistaabem/

Aróstegui, J.L. (2017). Neoliberalismo, Economía del Conocimiento y Educación Musical. Revista Electrónica Complutense de Investigación en Educación Musical, 14, 11-27. doi:10.5209/RECIEM.57044

Aróstegui, J.L. y Cisneros-Cohernour, E. (2010). Reflexiones en torno a la formación del profesorado a partir del análisis documental de los planes de estudio en Europa y América Latina. Profesorado. Revista de Currículum y Formación del Profesorado, 14(2), 179-189. Recuperado de: https://recyt.fecyt.es/index.php/profesorado/article/

Ballantyne, J. (2007). Integration, contextualization and continuity: Three themes for the development of effective music teacher education programmes. International Journal of Music Education, 25(2), 119-136. doi:10.1177/0255761407079955

Ceschini, J. (2014). STEM + art: A fruitful combination. Education Week, 34(13), 22-23. Recuperado de: https://www.edweek.org/ew/articles/2014/12/03/13ceschini.h34.html

Checa, R. (2004). Cambio de modelo en la formación del profesorado de las enseñanzas de Música. Revista Electrónica de LEEME, 14, 1-11. Recuperado de https://ojs.uv.es/index.php/LEEME/article/view/9749/9183

Cid, A., Sarmiento, J.A. y Pérez, A. (2012). Las concepciones sobre la enseñanza de los estudiantes que realizaron el CAP y el Máster de Educación Secundaria en la Universidad de Vigo. Revista de Investigación en Educación, 10(1), 100-114. Recuperado de: http://reined.webs.uvigo.es/index.php/reined/article/view/137

@Rosa María Serrano Pastor, Felipe Javier Zamorano Valenzuela y Cristina González Martín. The content of this article is the sole responsibility of the authors. The Revista Electrónica de LEEME and Universitat de València are not liable for any legal actions that may arise involving the article's content. Revista Electrónica de LEEME - Lista Electrónica Europea de Música en la Educación-. http://ojs.uv.es/index/php/LEEME/index ISSN: 1575-9563. Editores: Universidad de Valencia y Jesús Tejada. Visibilidad de esta revista: SCOPUS, Emerging Sources Citation Index (Clarivate), EBSCO, CINDOC (CSIC), Citefactor, COPAC, Dialnet, DICE (CSIC), DOAJ, e-revistas (CSIC), EBSCO Premier, ERIH+, Gale Cengage Learning, IN-RECS, IRESIE, LATINDEX, MIAR, OCLC Worldcat, RESH, REDIB, RILM Core Journals, SUDOC, ULRICHS. Esta revista es de acceso libre mediante licencia Creative Commons $4.0 \mathrm{CC}$ by. Política de archivado: etiqueta verde SHERPA-ROMEO. 
Domínguez, G. y Prieto, E. (2019). Experiencias y reflexiones sobre la formación inicial del profesorado de enseñanza secundaria: Retos y alternativas. Profesorado. Revista de Currículum y Formación del Profesorado, 23(3), 1-13. doi:10.30827/profesorado.v23i3.11229

Drucker, P.F. (1993). The rise of the knowledge society. The Wilson Quarterly, 17, 52-71. Recuperado de: https://bit.ly/35WLra1

Escudero, J.M., Campillo, M. y Sáez, J. (2019). El Máster de Formación Inicial del Profesorado de Educación Secundaria: Revisión, balances y propuestas de mejora. Profesorado. Revista de Currículum y Formación de Profesorado, 23(3), 165-188. doi:10.30827/profesorado.v23i3.9409

Fideli, R. (1998). La comparazione. Milán: Agneli.

Fox, V. (2005). Análisis documental de contenido: principios y prácticas. Buenos Aires: Alfagrama.

García-Gil, D. y Bernabé, M. (2019). Formación y preparación musical en el grado de Educación Infantil: Consideraciones de las alumnas en la Educación Superior. Prisma Social: Revista de Investigación Social, 25, 127-148. Recuperado de: https://revistaprismasocial.es/article/view/2692

Giddens, A. (1998). Más allá de la izquierda y la derecha: el futuro de las políticas radicales. Madrid: Cátedra.

Gil-Asensio, V. (2008). La guía docente: punto de partida para la concreción de un nuevo grado superior de música adaptado al Espacio Europeo de Educación Superior. Revista Electrónica de LEEME, 21, 17-28. Recuperado de: https://ojs.uv.es/index.php/LEEME/article/view/9771

Hernández, M.J. y Carrasco, V. (2012). Percepciones de los estudiantes del Máster en Formación del Profesorado de Educación Secundaria: fortalezas y debilidades del nuevo modelo formativo. Enseñanza \& Teaching, 30(2), 127-152. Recuperado de: https://revistas.usal.es/index.php/0212-5374/article/view/9318

Jamil, F.M., Linder, S.M. y Stegelin, D. (2018). Early childhood teacher beliefs about STEAM education after a professional development conference. Early Childhood Education Journal, 46(4), 409-417. doi:10.1007/s10643-017-0875-5

Jefatura del Estado (2007). Ley Orgánica 4/2007, de 12 de abril, por la que se modifica la Ley Orgánica 6/2001, de 21 de diciembre, de Universidades. BOE (13/04/2007), núm.89, referencia 7786, pp.16241-16260.

@Rosa María Serrano Pastor, Felipe Javier Zamorano Valenzuela y Cristina González Martín. The content of this article is the sole responsibility of the authors. The Revista Electrónica de LEEME and Universitat de València are not liable for any legal actions that may arise involving the article's content. Revista Electrónica de LEEME - Lista Electrónica Europea de Música en la Educación-. http://ojs.uv.es/index/php/LEEME/index ISSN: 1575-9563. Editores: Universidad de Valencia y Jesús Tejada. Visibilidad de esta revista: SCOPUS, Emerging Sources Citation Index (Clarivate), EBSCO, CINDOC (CSIC), Citefactor, COPAC, Dialnet, DICE (CSIC), DOAJ, e-revistas (CSIC), EBSCO Premier, ERIH+, Gale Cengage Learning, IN-RECS, IRESIE, LATINDEX, MIAR, OCLC Worldcat, RESH, REDIB, RILM Core Journals, SUDOC, ULRICHS. Esta revista es de acceso libre mediante licencia Creative Commons $4.0 \mathrm{CC}$ by. Política de archivado: etiqueta verde SHERPA-ROMEO. 
Jorgensen, E.R. (2003). Transforming music education. Bloomington, IN: Indiana University Press.

Jorquera, M.C. (2010). Modelos didácticos en la enseñanza musical: el caso de la escuela española. Revista Musical Chilena, 214, 52-74. Recuperado de: https://revistamusicalchilena.uchile.cl/index.php/RMCH/article/view/10571/10649

Kertz-Welzel, A. (2018). Globalizing Music Education: A framework. Bloomington: Indiana University Press.

Liston, D. y Zeichner, K. (1997). Formación del profesorado y condiciones sociales de la escolarización. Madrid: Ediciones Morata.

López, F. y Bermell, M.A. (2016). La especialidad de Música del Máster de Profesor de Educación Secundaria. Análisis de los planes de estudio de las universidades españolas ofertantes. Revista de Investigación en Educación, 14(2), 205-219. Recuperado de: http://reined.webs.uvigo.es/index.php/reined/article/view/214

Lucato, M. (2001). El método Kodály y la formación del profesorado de música. Revista Electrónica de LEEME, 7, 1-7. Recuperado de: https://ojs.uv.es/index.php/LEEME/article/view/9725/9161

Manso, J., Matarranz, M. y Valle, J.M. (2019). Estudio supranacional y comparado de la formación inicial del profesorado en la Unión Europea. Profesorado. Revista de Currículum y Formación del Profesorado, 23(3), 15-33. doi:10.30827/profesorado.v23i3.9697

Marcelo, C. (2001). Aprender a enseñar para la Sociedad del Conocimiento. Revista Complutense de Educación, 12(2), 531-593. Recuperado de: https://revistas.ucm.es/index.php/RCED/article/view/RCED0101220531A

Ministerio de Educación y Ciencia (2007a). Orden ECI/3858/2007, de 27 de diciembre, por la que se establecen los requisitos para la verificación de los títulos universitarios oficiales que habiliten para el ejercicio de las profesiones de Profesor de Educación Secundaria Obligatoria y Bachillerato, Formación Profesional y Enseñanzas de Idiomas. BOE (29/12/2007), núm.312, referencia 22450, pp.53751-53753.

Ministerio de Educación y Ciencia (2007b). Real Decreto 1393/2007, de 29 de octubre, por el que se establece la ordenación de las enseñanzas universitarias oficiales. $\mathrm{BOE}$ (30/10/2007), núm.260, referencia 18770, pp.44037-44048.

Nierman, G.E., Zeichner, K. y Hobbel, N. (2002). Changing Concepts of Teacher Education. En R. Colwell y C. Richardson (Eds.), The new handbook of research on music teaching

@Rosa María Serrano Pastor, Felipe Javier Zamorano Valenzuela y Cristina González Martín. The content of this article is the sole responsibility of the authors. The Revista Electrónica de LEEME and Universitat de València are not liable for any legal actions that may arise involving the article's content. Revista Electrónica de LEEME - Lista Electrónica Europea de Música en la Educación-. http://ojs.uv.es/index/php/LEEME/index ISSN: 1575-9563. Editores: Universidad de Valencia y Jesús Tejada. Visibilidad de esta revista: SCOPUS, Emerging Sources Citation Index (Clarivate), EBSCO, CINDOC (CSIC), Citefactor, COPAC, Dialnet, DICE (CSIC), DOAJ, e-revistas (CSIC), EBSCO Premier, ERIH+, Gale Cengage Learning, IN-RECS, IRESIE, LATINDEX, MIAR, OCLC Worldcat, RESH, REDIB, RILM Core Journals, SUDOC, ULRICHS. Esta revista es de acceso libre mediante licencia Creative Commons $4.0 \mathrm{CC}$ by. Política de archivado: etiqueta verde SHERPA-ROMEO. 


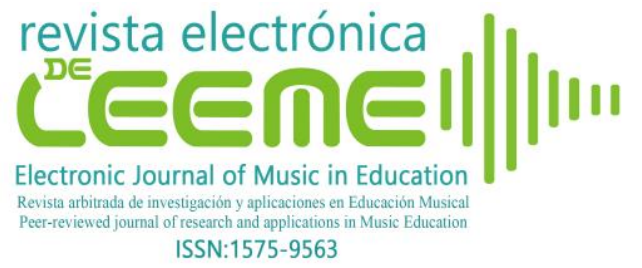

Rosa M. Serrano, Felipe Javier Zamorano y Cristina González Martín

El Máster en Profesorado de Música: análisis de los planes de estudio desde la perspectiva de la sociedad y economía del conocimiento (Revista Electrónica de LEEME) Número 48, pp. 187-207 https://ojs.uv.es/index.php/LEEME/index

and learning: a project of the music educators national conference (pp.818-839). Oxford: Oxford University Press.

Peña, T. y Pirela, J. (2007). La complejidad del análisis documental. Información, Cultura y Sociedad: Revista del Instituto de Investigaciones Bibliotecológicas, 16, 55-81. Recuperado de: https://dialnet.unirioja.es/servlet/articulo?codigo $=2501044$

Pontes, A., Ariza, L. y del Rey, R. (2010). Identidad profesional docente en aspirantes a profesorado de enseñanza secundaria. Psychology, Society, \& Education, 2(2), 131-142. Recuperado de: http://ojs.ual.es/ojs/index.php/psye/article/view/440

Popkewitz, T. y Pereyra, M. (1994). Estudio comparado de las prácticas contemporáneas de reforma de la formación del profesorado en ocho países: configuración de la problemática y construcción de una metodología comparativa. En T. Popkewitz (Comp.), Modelos de poder y regulación social en pedagogía (pp.15-94). Barcelona: Pomares-Corredor.

Riveiro, L.E. (2014). El conocimiento pedagógico y didáctico del profesorado de las Enseñanzas Artísticas Musicales. DEDiCA. Revista de Educaçao e Humanidades, 6, 295-308. Recuperado de: https://revistaseug.ugr.es/index.php/dedica/article/view/6981

Robelen, E.W. (2011). Building STEAM: Blending the arts with STEM subjects. Education Week, 31(13), 8-9. Recuperado de: https://www.edweek.org/ew/articles/2011/12/01/13steam_ep.h31.html

Scheib, J.W. (2006). Tension in the Life of the School Music Teacher: A Conflict of Ideologies. Update: Applications of Research in Music Education, 24(2), 5-13. doi:10.1177/87551233060240020101

Stehr, N. (2007). Societal transformations, globalisation and the knowledge society. International Journal of Knowledge and Learning, 3(2-3), 139-153. doi:10.1504/ijk1.2007.015548

Torres, J. (2006). Profesoras y profesores en el ojo del huracán. Foro de Educación, 7-8, 81102. Recuperado de: https://forodeeducacion.com/ojs/index.php/fde/article/view/211

Vaillant, D. (2019). Formación inicial del profesorado de Educación Secundaria en América Latina - Dilemas y desafíos. Profesorado. Revista de Currículum y Formación del Profesorado, 23(3), 35-52. doi:10.30827/profesorado.v23i3.9516

Zeichner, K. (1983). Alternative Paradigms of Teacher Education. Journal of Teacher Education, 34(3), 3-9. doi:10.1177/002248718303400302

@Rosa María Serrano Pastor, Felipe Javier Zamorano Valenzuela y Cristina González Martín. The content of this article is the sole responsibility of the authors. The Revista Electrónica de LEEME and Universitat de València are not liable for any legal actions that may arise involving the article's content. Revista Electrónica de LEEME - Lista Electrónica Europea de Música en la Educación-. http://ojs.uv.es/index/php/LEEME/index ISSN: 1575-9563. Editores: Universidad de Valencia y Jesús Tejada. Visibilidad de esta revista: SCOPUS, Emerging Sources Citation Index (Clarivate), EBSCO, CINDOC (CSIC), Citefactor, COPAC, Dialnet, DICE (CSIC), DOAJ, e-revistas (CSIC), EBSCO Premier, ERIH+, Gale Cengage Learning, IN-RECS, IRESIE, LATINDEX, MIAR, OCLC Worldcat, RESH, REDIB, RILM Core Journals, SUDOC, ULRICHS. Esta revista es de acceso libre mediante licencia Creative Commons $4.0 \mathrm{CC}$ by. Política de archivado: etiqueta verde SHERPA-ROMEO. 
Zeichner, K. (2005). Los profesores como profesionales reflexivos y la democratización de la reforma escolar. Docencia, II, 74-85. doi:10.1080/08897077.2013.770425

@Rosa María Serrano Pastor, Felipe Javier Zamorano Valenzuela y Cristina González Martín. The content of this article is the sole responsibility of the authors. The Revista Electrónica de LEEME and Universitat de València are not liable for any legal actions that may arise involving the article's content. Revista Electrónica de LEEME - Lista Electrónica Europea de Música en la Educación-. http://ojs.uv.es/index/php/LEEME/index ISSN: 1575-9563. Editores: Universidad de Valencia y Jesús Tejada. Visibilidad de esta revista: SCOPUS, Emerging Sources Citation Index (Clarivate), EBSCO, CINDOC (CSIC), Citefactor, COPAC, Dialnet, DICE (CSIC), DOAJ, e-revistas (CSIC), EBSCO Premier, ERIH+, Gale Cengage Learning, IN-RECS, IRESIE, LATINDEX, MIAR, OCLC Worldcat, RESH, REDIB, RILM Core Journals, SUDOC, ULRICHS. Esta revista es de acceso libre mediante licencia Creative Commons $4.0 \mathrm{CC}$ by. Política de archivado: etiqueta verde SHERPA-ROMEO. 